\title{
Cities in the experience economy: the rise and the future of urban leisure formats
}

\author{
Piotr Zmyslony and Karolina Anna Wędrowicz
}

\begin{abstract}
Purpose - The purpose of this paper is to discuss the rise and the future of urban leisure format (ULF), i.e. local seasonal short-lived and repeatable small-scale place-time-based staging urban leisure experiences which become the focus of recreation and tourism development in many cities. It aims to analyse the structure of the ULF by identifying its main features and also to propose the future developments of the concept.

Design/methodology/approach - The study is based on the experience economy principles. It develops the models for structured experiences/experienscape by adding the analogy with television programme formats to propose the general logic of constructing, organising and packetizing urban leisure experiences that are multiplied effectively to other urban time-spaces.

Findings - The ULF's future potential lies in its ability to adopt local components, i.e. people and urban resources, to global trends using a structured experiences/experience logic which makes the ULF formattable, i.e. with the capacity to get informally standardised, then repeated and adapted to other cities' contexts.

Research limitations/implications - The paper provides a conceptual framework for formatting the leisure events and places under the framework of the structured experience, will be carefully adapted to the micro-local level, i.e. community activities sphere. The ULF is a theoretical concept and needs empirical research to verify its validity.

Practical implications - The ULF provides urban managers with a framework for replicating, multiplying and adapting urban leisure events and sites within the structured experiences (SE) designing framework. Originality/value - The study contributes to the scientific discussion on the experience economy by introducing the ULF concept which can be adapted to various urban conditions.
\end{abstract}

Keywords Trends, Urban leisure, Urban tourism, City tourism, Structured experiences concept, Experienscape, Experience economy

Paper type Viewpoint

\section{Introduction}

Since human and creative capital became the theoretical background of urban development, consumption, leisure and tourism have been recognised as crucial drivers of city competitiveness and regeneration of urban space (cf. Clark, 2004; Florida, 2002). It has been manifested by developing spectacular commercial leisure spaces and cultural investment projects aimed at attracting mobile global capital (cf. Dziembowska-Kowalska and Funck, 1999; Silk and Andrews, 2006), re-enchanting of up-scale urban leisure settings (Ritzer, 2005) as well as at establishing semi-formal creative quarters and entertainment zones (Pappalepore et al., 2014; Roberts and Eldridge, 2012) and producing public-driven urban spectacles (Gotham, 2005).

Inconclusive experiences resulting from these changes (cf. Florida, 2017; Gravari-Barbas and Guinand, 2017; Zukin, 2008) have shifted the urban focus towards local seasonal short-lived and repeatable small-scale place-time-based staging leisure experiences. The examples are showcase festivals; organised meetings spots; culinary events; outdoor dance zones; transitory waterfront objects and serious leisure events. They are much less interfering with space and less disruptive concerning the existing urban landscape than the previous urban leisure forms.

However, the local manner of producing these leisure forms does not imply their local, authentic nature. This is because their rise is also demand-driven. It has resulted from globalised attitudes of
Piotr Zmyslony is based at the Department of Tourism, Faculty of International Business and Economics, Poznań University of Economics and Business, Poznań, Poland.

Karolina Anna Wędrowicz is based at Destination Marketing Agency, Poznań, Poland.

Received 24 January 2019

Revised 26 June 2019

Accepted 27 June 2019

(C) Piotr Zmyslony and

Karolina Anna Wędrowicz.

Published in Journal of Tourism

Futures. Published by Emerald

Publishing Limited. This article is published under the Creative Commons Attribution (CC BY 4.0)

licence. Anyone may reproduce, distribute, translate and create derivative works of this article (for both commercial and non-

commercial purposes), subject to full attribution to the original publication and authors. The full terms of this licence may be seen at http://creativecommons.org/ licences/by/4.0/legalcode 
modern urban consumers - both residents and visitors - as regards the ways to spend leisure time as well as their striving for maximising the value of experience they obtain while reducing their efforts relating to the process of designing them thanks to information technology revolution (cf. Angus and Westbrook, 2019; Buhalis and Sinarta, 2019; Croce, 2018; Dujmović and Vitasović, 2015).

We argue that a "light" formula and an ability to design the structured experiences (SE) within the new leisure forms make them formattable, i.e. with the capacity to get informally standardised, then repeated and adapted to other cities' contexts, even though they are locally organised. Eventually, they are replicated transnationally, following the logic known from media industry as television programme format (Chalaby, 2012; Moran, 2009), in which localism is not a resource to preserve but a context to adapt to the central theme. Therefore, we propose the "urban leisure format" (ULF) term to reflect these specific forms of interactive social spaces.

This viewpoint paper aims to analyse the conceptual structure of the ULF by identifying its main features and also to propose the future developments of the concept. We argue that this is a staging SE logic (Pine and Gilmore, 1999) within the local context and not a taste of local authenticity (cf. Zukin, 2008) or significant investment projects which makes the ULF a scheme of making urban space-time attractive for residents and tourists; the scheme capable of being standardised and replicated in other cities. Thus, we apply the framework of the SE (Duerden et al., 2015; Ellis et al., 2019), the model of staging recreational encounters (Ellis and Rossman, 2008) and experienscape concept (Pizam and Tasci, 2019) as a theoretical framework for analysing the ULF's structure, and the television format scheme (Chalaby, 2012; Moran, 2009) to discuss its formatting potential.

The paper is addressed to the academics interested in the experience economy concepts within urban leisure context. Moreover, local associations and activists can use the ULF framework to discuss their ideas for attracting urban time-space in their city.

\section{Theoretical and conceptual foundations}

Three aspects should be highlighted as a theoretical background of the study: changes in consumer behaviour; staging structured experiences; and TV format mechanism.

\section{Changes in consumer behaviour in leisure time}

The rolling revolution of technology and accompanying changes in consumer lifestyles have led to the technological shift which affects, primarily, $Y$ and $Z$ generations; however, it impacts all modern societies (Angus and Westbrook, 2019; Croce, 2018; Dujmović and Vitasović, 2015; Haddouche and Salomone, 2018; Prahalad and Ramaswamy, 2004). Leisure time consumers are networked, active and well informed, so they evince a need to spend it consciously due to maximising the value of the experience they obtain. Prioritising experiences becomes the central value of consumers' buying decisions and the capital of their social identity shaped in real-time via social media (Buhalis and Sinarta, 2019; Nedra et al., 2019). Places they visit and events they have experienced become the components of their "spatial selves" (Schwartz and Halegoua, 2015) that are created to be positively received and compared by others. Technology has also made consumers reduce the personal opportunity costs relating to the process of designing their experiences in favour of an anticipation of organised and packetized urban leisure offering which they could consume in their leisure time (Angus and Westbrook, 2019).

\section{Staging structured experiences}

In line with the experience economy logic (Pine and Gilmore, 1999), experiences take a form of co-produced affairs where participants are perceived as active agents and not passive spectators (Ellis and Rossman, 2008). Duerden et al. (2015) conceptualise SE concept which consists of two dimensions: the experience co-creation process referring to objective, interactive encounters among consumers and provider-manipulated framework as well as the participant's subjective outcomes of experiences; experience phases referring to anticipation, participation, and reflection and integration processes which happen to the participants (Duerden et al., 2015). Ellis et al. (2019) extend the concept into a theory by proposing a set of 
experiential results felt by participants at the time of staging, i.e. immersion, absorption, engagement, which can all be "invited" but not controlled by providers, and result in deeply-structured experiences. They also add an evaluated experience component which is built individually by participants after an encounter and which refers to the perceived value of experience, affect, and delight.

The model of staging recreational experiences (SRE) proposed by Ellis and Rossman (2008, p. 4) refers to "economic offerings in which guests exchange something of value from a variety of opportunity costs to receive a valued emotional and motivational experience[s]". The additional benefits are long-term cherished memories and educational, therapeutic, or developmental transformations of participants (Ellis and Rossman, 2008). According to the model, successful staging experiences by providers require designing technical performance and artistic performance of an encounter in order to facilitate and yield individual experiences, "presenving the autonomy of the participant to help create the leisure experience as well as the freedom to do so" (Ellis and Rossman, 2008, p. 13).

The experienscape concept characterised by Pizam and Tasci (2019) develops an established and widely researched servicescape concept (cf. Tumbat and Belk, 2013; Wakefield and Blodgett, 1996) by adding the multistakeholder approach and focusing on experiential consumption framework. Experienscape refers to "the sensory, functional, social, natural, and cultural stimuli in a product or service environment, surmounted with a culture of hospitality, all of which accrue to an experience for consumers, employees, and other stakeholders and result in positive or negative cognitive, affective, and behavioural reactions towards products, services, brands, and firms" (Pizam and Tasci, 2019, p. 34).

\section{TV format}

According to Moran (2009, pp. 115-116), a TV programme format refers to "a method of practising television whereby a kind of unspecific, universal or denationalised programme template or recipe is developed, which in turn can be customised and domesticated for reception and consumption by specific audiences in local or national contexts". As the TV programme format is franchised, it transfers the expertise written in detailed format rules, which are designed to create dramatic arcs and produce storylines. The rules are divided into those that determine the format core and thus are fixed and those which enable to tailor the programme to local audiences and apply the local knowledge (Chalaby, 2011). The distinct feature of the TV formats is transnationalism, which is "underlined by their hybrid nature since they adapt as they travel. In many instances, the knowledge acquired in different territories helps to refine the rules that make a format a unique show" (Chalaby, 2011, p. 296).

\section{The essence of urban leisure format}

The ULF is a temporary (usually seasonal) short and repeating small-scale and low-budgetorganised outdoor area or event, aimed at creating a replicable, thematic, structured and placetime-based staging leisure experiences. Thus, these areas or events are usually locally organised and community-driven or owned (by neighbourhood associations, urban social movements or local entrepreneurs and activists) with participation, commission or permit from local government agencies as they take place and are set in a public space. Table I presents the most popular types of the ULF and their main components.

The ULF is an emerging concept so it will remain flexible and its standards and practices will be shaped in the future. Moreover, the examples presented in Table I certainly do not exhaust the possibilities and the potential development forms that the concept creates. The types could also be mixed as they establish a core experience. However, it is possible to define its key attributes.

\section{A permanent set of complementary leisure activities formed an encounter core experience}

Every type of the ULF is based on a specific principle value; however, what constitutes a format is a bundle of complementary elements of an offering composed around it that structure consumers' experiences. Therefore, the offering is designed with both experiential and spatial logic, forming zones separated formally or symbolically from one other, i.e. catering zone, meeting 
Table I Urban leisure formats: types and components

\begin{tabular}{|c|c|c|}
\hline Type/example & Main theme/experience core & Complementary components \\
\hline $\begin{array}{l}\text { Urban art and } \\
\text { culture festivals }\end{array}$ & $\begin{array}{l}\text { Participation in plays, concerts, } \\
\text { exhibitions, etc. }\end{array}$ & $\begin{array}{l}\text { Catering zone, outdoor/indoor dance zone, art and craft workshops, Q\&A, conferences, } \\
\text { socialising zone, relax zone, complementary art performances, playground/kindergarten } \\
\text { zone, first-aid zone, sanitary facilities, merchandising zone }\end{array}$ \\
\hline $\begin{array}{l}\text { Day/evening } \\
\text { socializing spots }\end{array}$ & Socialising, partying & $\begin{array}{l}\text { Catering zone, relax zone, DJs music, live music concerts, outdoor dance zone, art and } \\
\text { craft workshops, debates and formal meetings, playground/kindergarten zone, sanitary } \\
\text { facilities, merchandising zone }\end{array}$ \\
\hline Open-air cinemas & Watching a film & $\begin{array}{l}\text { Catering zone, socialising zone, relax zone, DJ music, sanitary facilities, merchandising } \\
\text { zone }\end{array}$ \\
\hline $\begin{array}{l}\text { Serious leisure } \\
\text { events }\end{array}$ & $\begin{array}{l}\text { Active participation/supporting } \\
\text { sport contest }\end{array}$ & $\begin{array}{l}\text { Fan-competitor-mixed zone, catering zone, medal ceremony, socialising zone, relax zone, } \\
\text { playground/kindergarten zone, sanitary facilities, artistic performances, parking area }\end{array}$ \\
\hline $\begin{array}{l}\text { Outdoor dance } \\
\text { zones }\end{array}$ & Collective dancing & $\begin{array}{l}\text { Catering zone, live music, dancing training courses, artistic performances, socialising zone, } \\
\text { relax zone, playground/kindergarten zone, sanitary facilities }\end{array}$ \\
\hline Local fan zones & $\begin{array}{l}\text { Collective excitement over a live- } \\
\text { streaming sport event }\end{array}$ & $\begin{array}{l}\text { Organised support, catering zone, socialising zone, relax zone, DJ and live music, sanitary } \\
\text { facilities, playground/kindergarten zone }\end{array}$ \\
\hline $\begin{array}{l}\text { Culinary events/ } \\
\text { food fests }\end{array}$ & $\begin{array}{l}\text { Tasting food, enjoying culinary } \\
\text { culture }\end{array}$ & $\begin{array}{l}\text { Culinary courses, conferences, merchandising, thematic food fairs, socialising zone, relax } \\
\text { zone, DJ and live music, sanitary facilities, playground/kindergarten zone }\end{array}$ \\
\hline $\begin{array}{l}\text { Urban beaches/ } \\
\text { waterfront areas }\end{array}$ & Relaxing and socialising & $\begin{array}{l}\text { Catering zone, live DJs music concerts, artistic performances, beach furniture rental, boat \& } \\
\text { kayak rentals, organised boat trips, dancing training courses, playground/kindergarten } \\
\text { zone, merchandising zone, sanitary facilities }\end{array}$ \\
\hline $\begin{array}{l}\text { Street parades and } \\
\text { marches }\end{array}$ & Collective manifesting & $\begin{array}{l}\text { Catering zone, relax zone, debates and formal meetings, DJs music, live music concerts, } \\
\text { merchandising zone, costume competitions, sanitary facilities }\end{array}$ \\
\hline
\end{tabular}

zone, merchandising zone, relax zone, sanitary and first-aid zone. They are all staged as one so that the consumers, regardless of the core they are interested in and the city where the event is located, can expect the availability of a specific infrastructure and services in the designated area.

\section{Parallel individualisation and standardisation of experience}

The design of the ULF focuses on the maximisation of a participant's personal experience which cocreates its utility, and the final success of both the format and the participants' performed and shared life events. According to the experience theory principles (Pine and Gilmore, 1999), participants are given a "manipulated" free choice; providers intentionally offer a design of staging encounters, and the participants compose their overall individual experience, determining when, what, and what form their experience assumes. Thus, the ULF proposes a framework that enables participants to perform their social identities or "spatial self" (cf. Schwartz and Halegoua, 2015) as a co-created part of the ULF. The individualisation of experience is provided together with satisfying the participants' need to receive a design of SE corresponding to the ULF type arranged according to a specific value staging scheme. Thus, participants are even more aimed at SE intentionally staged by local providers.

\section{Temporality and interlocking forms of spending leisure time}

The ULFs are temporal, i.e. most often of seasonal nature. Recreants most often get involved in the ULF for two reasons: driven by the principal value or attracted by other participants' shared experience and feedback. The values that universally specify the ULF is socialising as well as spending time with friends and family and meeting new people. Thus, the ULF is based on collective experience built during the co-creation process among participants, providers and the city. That is why several leisure activities and experiences take place simultaneously (e.g. concert, meeting zone, gastronomy, merchandising), intentionally manipulated by providers and co-created by participants.

\section{Informally separated space and lack of hard architecture}

Most of the ULF forms are organised outdoors or at least partly outdoors. Most often, for the duration of a given event or staging an encounter offering, informally or symbolically but clearly separated space is created, and the elements of the necessary infrastructure of a temporary character are built (e.g. platforms, routes, sanitary facilities, food tracks, urban furniture, seats and hammocks). 


\section{Flexible time spent at a place/event}

Even though SE have definable beginning and ending points (Ellis et al., 2019), the time of participation in an ULF is not dependent on the duration of its performing or functioning. Choosing to participate in a given ULF, a guest takes part not only in the core event but also experiences other available forms of leisure before and after. The specific time that participants intend to spend at an ULF event is not usually top-down determined or set in advance. The ULF events last relatively longer as compared to traditional events. Therefore, the ULF experience is designed by the local providers in such a way as to induce respondents to co-create the duration of their experiences.

\section{Local and participant communities focused around a given format}

The ULF is generally co-created by both local social associations and urban activists or entrepreneur groups and also by its "community" of fans or supporters who are visible both at the place and in social media. These groups often gain a certain level of homogeneity as the participation is often associated with a specific lifestyle and professed values, and taking part in a given ULF becomes an opportunity to manifest them. However, the ULF is regarded to be an interspace between residents' and visitors' global community. Also, the participants can be seriously involved in it and show their interest not only throughout its duration but also before and after it is over. The existence of a community facilitates useful feedback and the ULF experience co-creation through interactive communication between the organisers and participants through social media.

\section{Repeatability, replicability and adaptability}

Each ULF type is a kind of a characteristic event organisation pattern, based on a given core and complementary services, offered in a characteristic manner and setting, at a specific time and place. This scheme can be freely repeated in time and space by organising subsequent editions of an event, replicating in other cities or adapting it by enriching the core so that the event gains a new central theme. None of these changes, however, affect the clarity of the theme and organisational principles characterising the format. The ULF participants, regardless of the place, time or subject of an event, can navigate their individual "route" or "board", feeling confident about what to expect. Nevertheless, it is every city's identity and heritage that make the ULF flexible.

\section{Discussion and implications: the present and future of ULF}

The ULF concept has a practical origin as it derived from critical observation and anticipation of the evolution of leisure initiatives developing nowadays in European urban areas as well as from the need to find a scientific framework to explain this phenomenon. Therefore, its potential utility is possible after the verification of its reference to the models and theories described as its theoretical and conceptual framework.

Table II collates the following ULF's attributes with specific elements of the SRE model (Ellis and Rossman, 2008); the SE concept (Duerden et al., 2015; Ellis et al., 2019); and the experienscape model (Pizam and Tasci, 2019). Each of these attributes can be at least theoretically explained and, in most cases, even managerially applied, using the logic of experience economy principles. In particular, the SRE and experienscape frameworks suggest the components that should be used to emphasise each ULF attribute. At the same time, the SE concept provides a logical explanation of the impact of the attributes on the participants' behaviours and reactions.

Adapting the SE frameworks into an urban context on a micro scale, the ULF scheme reverses the previous logic of enhancing and utilising local attractiveness (cf. Zukin, 2008). In this case, it is not about putting a sense of local authenticity in the core of the ULF, but about adopting localities to transnational trends which make it formattable. According to Table II, cities will be able to impress their local peculiarities and uniqueness forming the format-flexible components (i.e. unanticipated value or interpersonal performance) presented in repeatability, replicability and adaptability features of the ULF. However, the condition is to meet global consumer expectations regarding the experiences and structure of services described as other features. Raising consumers' expectations towards the structuring of the 
Features of ULF/reference areas

Staging recreational experiences Structured experiences concept/theory (Duerden model (Ellis and Rossman, 2008) et al., 2015; Ellis et al., 2019)

A permanent set of complementary leisure activities formed an encounter core experience

Parallel individualisation and standardisation of experience

Temporality and interlocking forms of spending leisure time

\section{per}

Theme performance

Multi-sensory staging

performance

Unanticipated value performance

Setting performance

Interpersonal performance

Theme performance

Technical skills performance

Setting performance

Multi-sensory staging

performance

Multi-sensory staging

performance

Interpersonal performance

Setting performance

Informally separated space and Technical skills performance lack of hard architecture

Flexible time spent at a place

Setting performance

Multi-sensory staging

performance

Determined individually by an

impact of others participants' cocreated and shared experiences Interpersonal performance

Repeatability, replicability and adaptability

Local and participant communities focused around a given format
Format-determined components explained by:

Theme performance

Technical skills performance

Multi-sensory staging

performance

Setting performance

Format-flexible components

determined by:

Unanticipated value performance

Interpersonal performance

Multi-sensory staging

performance

Unanticipated value performance

Interpersonal performance

Theme performance
Impact on participants' immersion, absorption, engagement, and - consequently - the overall participants' evaluated experiences, i.e. the

perceived value of an event, affect and delight

Influence on all experience phases: anticipation, participation/consumption, reflection and integration, both at the place of event or via social media

Influence on the intensity of participants' lived and evaluated experiences

Provider's components, especially service quality components influencing the level on participants' absorption and engagement

Determined individually by an intensity of an individual's level of immersion, absorption and engagement

Determined by co-creation process

Determined by technical performance, structure, animation and setting components delivered by providers due to the direct control over the participants' leisure experiences during the participation phase

Based on feedback loops interactions: each perceived experience during the event influences participants' relationships, thoughts, emotions, activities and memories they will bring and stage in the event:

providers modify experience elements based upon participants' feedback in order to improve the event;- participants share their perceived experiences with peers via social networks and thus these peers must be perceived as indirect participants whose attitudes and opinions about the provided and shared experience also influence the co-creation process of the event
Experienscape concept (Pizam and Tasci, 2019)

Sensory component Functional component Hospitality culture

Social component Functional component Sensory component Impact on response operators (personal and situational)

Sensory component Functional component Natural component Cultural component Hospitality culture Sensory component Functional component Natural component

Determined by emerging of a stimuli and their response

Social component Repeatability and replicability elements determined by: Functional component Social component Adaptability element determined by: Sensory component Natural component Cultural component Hospitality culture

Social component Hospitality culture

offering will be a rationale for the constant format development, both formally and informally. It will also deepen participants' absorption and engagement into an event by strengthening the sense of physical, social or psychological security and familiarisation with the event while participating in it even during the first-time visit in a city. Thus, the authenticity of locality will tailor the ULF and not format its core. 
As can be seen in Table II, the performance of each of the ULF attributes is dependent upon the broad context of the co-creation process between local providers and consumers. Considering the formerly presented directions of the changes in consumer behaviour, adapting global themes and staging structured encounters, into which the local context will be pressed, will be more important than the creation of strictly local experiences that carry the risk of failing to reach a wide, universal audience of visitors and residents. In the near future, new types of the ULF will emerge that promise an elastic core and formattable structure of the ULF. Their origin will vary as it was in the case of outdoor dance zones called milongas which were born in Latin America cities and spread worldwide.

Since the ULF is an emerging concept, the format rules of particular ULF types presented in Table I, now produced informally, will change into formal narrative dimension and expertise transfer. The ULF will gain formal replicability. It might lead to their homogenisation caused by standardisation processes described by Ritzer (2005) and commodifying the public spaces described by Zukin (2008). The further development of digital technology and the rising emphasis of dwellers and visitors on SE offerings will lead to a rationalisation of the ULF as leisure. ULFs will possibly be capitalised in the form of chain or franchising as it happened after liberalisation of alcohol trading in Great Britain in 1990 (cf. Roberts and Eldridge, 2012).

\section{Conclusion}

The study contributes to the scientific discussion on the experience economy by introducing the urban leisure format concept which can be adapted to various urban conditions. Its logic lies in the preparation of a universal composition with global coverage using local components, i.e. people and urban resources. The paper provides the ULF conceptual structure by discussing its main features. The structured experiences framework has been and will be transferred to the urban context; however, not to the urban space as w whole, but its individual places. We argue that this framework will be closely adapted to the micro-local level, i.e. community activities sphere, which causes global copying and spreading of temporal time-spaces, simultaneously attracting the sense of global consumer security and ensuring the local atmosphere of the city, both of them contained in a format idea. Therefore, we enter an era of the commodification of local structured experiences.

The ULF is a theoretical concept and needs empirical research to verify its validity. Moreover, the nature of the article did not allow for a comprehensive analysis of the potential adverse effects of the universalisation of the concept in cities. Further research should also focus on the consequences of dissemination of the ULF for the local neighbourhood.

\section{References}

Angus, A. and Westbrook, G. (2019), "Top 10 global consumer trends 2019", Euromonitor International, available at: https://go.euromonitor.com/white-paper-EC-2019-Top-10-Global-Consumer-Trends.html (accessed 17 January 2019).

Buhalis, D. and Sinarta, Y. (2019), "Real-time co-creation and nowness service: lessons from tourism and hospitality", Journal of Travel \& Tourism Marketing, Vol. 36 No. 5, pp. 563-82.

Chalaby, J.K. (2011), "The making of an entertainment revolution: how the TV format trade became a global industry", European Journal of Communication, Vol. 26 No. 4, pp. 293-309.

Chalaby, J.K. (2012), "At the origin of a global industry: the TV format trade as an Anglo-American invention", Media, Culture and Society, Vol. 34 No. 1, pp. 36-52.

Clark, T.N. (Ed.) (2004), "The city as an entertainment machine", Research in Urban Policy, Vol. 9, Elsevier, Oxford, pp. 1-325.

Croce, V. (2018), "With growth comes accountability: could a leisure activity turn into a driver for sustainable growth?", Journal of Tourism Futures, Vol. 4 No. 3, pp. 218-32.

Duerden, M.D., Ward, P.J. and Freeman, P.A. (2015), "Conceptualizing structured experiences: seeking interdisciplinary integration”, Journal of Leisure Research, Vol. 47 No. 5, pp. 601-20.

Dujmović, M. and Vitasović, A. (2015), "Postmodern society and tourism", Journal of Tourism and Hospitality Management, Vol. 3 Nos 9-10, pp. 192-203.

VOL. 5 NO. $22019 \mid$ JOURNAL OF TOURISM FUTURES $\mid$ PAGE 191 
Dziembowska-Kowalska, J. and Funck, R. (1999), "Cultural activities: source of competitiveness and prosperity in Urban Regions”, Urban Studies, Vol. 36 No. 8, pp. 1381-98.

Ellis, G.D. and Rossman, J.R. (2008), "Creating value for participants through experience staging: parks, recreation, and tourism in the experience industry", Journal of Park and Recreation Administration, Vol. 26 No. 4, pp. 1-20.

Ellis, G.D., Freeman, P.A., Jamal, T. and Jiang, J. (2019), "A theory of structured experience", Annals of Leisure Research, Vol. 22 No. 1, pp. 97-118.

Florida, R. (2002), The Rise of the Creative Class: And how it's Transforming Work, Leisure, Community and Everyday Life, Basic Books, New York, NY.

Florida, R. (2017), The New Urban Crisis: How Our Cities Are Increasing Inequality, Deepening Segregation, and Failing the Middle Class and What We Can Do About It, Basic Books, New York, NY.

Gotham, K.F. (2005), "Theorizing urban spectacles", City, Vol. 9 No. 2, pp. 225-46.

Gravari-Barbas, M. and Guinand, S. (Eds) (2017), Tourism and Gentrification in Contemporary Metropolises, Routledge, Oxon.

Haddouche, H. and Salomone, C. (2018), "Generation Z and the tourist experience: tourist stories and use of social networks", Journal of Tourism Futures, Vol. 4 No. 1, pp. 69-79.

Moran, A. (2009), "Global franchising, local customizing: the cultural economy of TV program formats", Continuum, Vol. 23 No. 2, pp. 115-25.

Nedra, B.A., Hadhri, W. and Mezrani, M. (2019), "Determinants of customers' intentions to use hedonic networks: the case of Instagram", Journal of Retailing and Consumer Services, Vol. 46, pp. 21-32.

Pappalepore, I., Maitland, R. and Smith, A. (2014), "Prosuming creative urban areas. Evidence from East London", Annals of Tourism Research, Vol. 44 No. 1, pp. 227-40.

Pine, B.J. and Gilmore, J.H. (1999), The Experience Economy: Work is Theatre and Every Business a Stage, Harvard Business School Press, Boston, MA.

Pizam, A. and Tasci, A.D.A. (2019), "Experienscape: expanding the concept of servicescape with a multi-stakeholder and multi-disciplinary approach", International Journal of Hospitality Management, Vol. 76, Part B, pp. 25-37.

Prahalad, C.K. and Ramaswamy, V. (2004), "Co-creation experiences: the next practice in value creation", Journal of Interactive Marketing, Vol. 18 No. 3, pp. 5-14.

Ritzer, G. (2005), Enchanting a Disenchanted World: Continuity and Change in the Cathedrals of Consumption, Sage Publications, New York, NY.

Roberts, M. and Eldridge, A. (2012), Planning the Night-Time City, Routledge, New York, NY.

Schwartz, R. and Halegoua, G.R. (2015), "The spatial self: location-based identity performance on social media", New Media and Society, Vol. 17 No. 10, pp. 1643-60.

Silk, M.L. and Andrews, D.L. (2006), "The Fittest City in America", Journal of Sport and Social Issues, Vol. 30 No. 3, pp. 315-27.

Tumbat, G. and Belk, R.W. (2013), "Co-construction and performancescapes", Journal of Consumer Behaviour, Vol. 12 No. 1, pp. 49-59.

Wakefield, K. and Blodgett, J. (1996), "The effect of the servicescape on customers' behavioral intentions in leisure service settings", Journal of Services Marketing, Vol. 10 No. 6, pp. 45-61.

Zukin, S. (2008), "Consuming authenticity: from outposts of difference to means of exclusion", Cultural Studies, Vol. 22 No. 5, pp. 724-48.

\section{Corresponding author}

Piotr Zmyslony can be contacted at: piotr.zmyslony@ue.poznan.pl

For instructions on how to order reprints of this article, please visit our website:

www.emeraldgrouppublishing.com/licensing/reprints.htm

Or contact us for further details: permissions@emeraldinsight.com 